\title{
Desire: The Neurophysiology of Morality
}

\author{
... then the Lord God formed man ... \\ and breathed into his nostrils the breath of life; \\ Genesis 2:7 NRSV
}

Breath is movement-movement into life. In psychological and biological terms movement is desire. In religious and spiritual terms it is God's desire that creates desire within human beings and we model ourselves on God's desire by imitating it.

In the previous chapter, we discovered how intersubjectivity involves desire, which is mediated by our human anatomy. We learned that the eyes of caregivers looking at an object transform the object into one that infants desire. Also, in the previous chapter we saw in a schematic that one of Scotus's two dimensions of morality is "free will/desire."

In this chapter we ascertain what psychiatry and neuroscience tell us about human neurophysiology and desire. We also address Scotus and desire.

Scotus and desire. If you refer back to chapter 3 for the schematic of Scotus's conceptualization of morality, you will remind yourself of the dimension of morality that Scotus calls "free will/desire." In chapter 3 we focused on the other dimension of morality: "intellect/cognition." In this chapter, we focus on desire. In chapter 5, we will focus on free will.

Desire, according to Scotus, exists in two orientations: desire for the self (affectio commodi) and desire to love justly (affectio iustitiae). The desire for the self is human desire focused inward toward self-preservation. The desire to love justly is human desire focused outward toward love of the good (Ingham, 1996). Both orientations of desire are inclined toward good. This means that both orientations of desire actively move toward good. Desire to love justly, however, is superior to desire for the self because it desires a thing for its own sake rather than for the benefit of the self. Furthermore, desire to love justly is never immoderate as desire for the self often is.

Note what is important!

Desire-in both orientations-is active. It is not passive. It is not something that happens to us. Desire is an active movement of our human inclination either inward toward self-enhancement or outward toward love of the good.

Desire for self-enhancement. To repeat, the desire for self-enhancement (affectio commodi) is human desire focused inward. It is an inclination for self- 
preservation, self-perfection and happiness; it is "the disposition whereby the will is drawn to love goods that bring pleasure and enjoyment to the self" (Ingham, 2003, 226). To quote Scotus' Ordinatio III, suppl., dist. 46, "The other act [of wanting something for oneself] ... has an affection for the advantageous [to the self]" (Wolter, 1986/1997, 153).

Scotus discerns that desire focused inward toward self-enhancement is perfected by hope (Wolter, 1986/1997, 13). Let us hasten to peek at how neuroscience seems to be affirming Scotus's insight. Neuroscience says that our desire focused inward must be activated. It is activated by being met and felt by another who responds to us with love (Morrison \& Severino, 2009). Desire focused inward toward self-enhancement is perfected by hope that we will be met harmoniously by another just as the Biblical creation story portrays God's meeting us. God meets us and breathes into us the breath of life.

Desire to love justly. Desire for justice (affectio iustitiae) is human desire focused outward. It is an inclination to love the good; it is the "disposition whereby the will is drawn to love the good because of its intrinsic value... and not because of any personal gain" (Ingham, 2003, 225). In Scotus' words, "To love something in itself [or for its own sake] is more an act of giving or sharing and is a freer act than is desiring that object for oneself. As such it is an act... of ... innate justice at least" (Wolter, 1986/1997, 153).

Scotus sees desire for justice "as both innate and inalienable, as an inclination of the will that all human beings have..." (Kent, 1995, 196). All human beings can desire justice. Even non-Christians can perform charitable acts and nourish a disposition to choose such acts. Our desire for justice motivates us but does not determine our choice. Using free will-as we address in chapter 5-we decide our choice of action.

Scotus discerns that desire focused outward to love justly is perfected by charity (Wolter, 1986/1997, 13). Peeking at neuroscience, we see that-like our desire to love the self-our desire to love justly must be activated. It is activated by being received by another (Morrison \& Severino, 2009). Desire focused outward to love justly is perfected by receipt of our charity - by receipt of our giving-and is rewarded with gratitude expressed by the recipient. Moreover, when our giving is motivated by love, it is pleasing to God who rewards us with life eternal.

Once the two orientations of our desire-the desire for self and the desire for justice-are ignited, human beings strive throughout life to unite them such that the morally good act is a beautiful whole of loving self and loving others. In other words, people are truly themselves when they "bring love for the self [affectio commodi] into harmony with love for the good [affectio iustitiae]" (Ingham, 2002, 101). Within this beautiful whole, human beings live with integrity of character, which is their source of happiness (Wolter, 1986/1997, 155-162) and dignity. Ordered love, thus, defines human dignity and reflects the most perfect morality where it channels our desire into doing what is right and good. 
Human neurophysiology and desire. Stephen W. Porges, Ph.D., Director of the Brain-Body Center in the Department of Psychiatry at the University of Illinois at Chicago, studies neurophysiology. He focuses on the neurophysiological substrates of human social communication and engagement within which moral issues are experienced and expressed. His perspective of neurophysiology complements what we learned in chapter 3 when we looked at the perspective of neuroanatomy. Neuroanatomy with its mirror neuron mechanism is necessary but insufficient to explain how the intentions behind bodily motions are understood. Turning to physiology helps. Together our physiology and our anatomy contribute to our human moral body. Together they equip us to assess others' intentions and our environment.

I find Porges's contributions about human neurophysiology significant because he addresses non-conscious mechanisms. So much of our moral behavior is non-consciously determined. Porges's theory gives us a way to understand how we automatically behave as we do.

Porges (2011) proposes that human beings have four ${ }^{5}$ primary mechanismsgoverned differently by our brain and body-for assessing our environment for safety or danger, and responding accordingly:

- Social engagement, enabling us to connect with others to feel safe, to remain calm and to access higher brain functioning for resolving situations;

- Mobilization, enabling us to fight or flee;

- Immobilization with fear, enabling us to go unseen, appear dead or dissociate from pain and terror; and

- Immobilization without fear, enabling women to nurse, to give childbirth and to engage in reproductive behaviors; and enabling all of us to engage in digestive and restorative processes.

Different environments shift our body's physiological states and shifting physiological states change the way we perceive reality and change our behavior.

Porges calls the process by which we automatically and non-consciously assess our environment and others' intentions "neuroception" (Porges, 2004). Neuroception is how we neurologically perceive our environment and others' intentions. We use our autonomic nervous system.

As we see in Table 4.1 our nervous system is anatomically divided into the central nervous system (our brain and spinal cord) and the peripheral nervous system (our spinal and cranial nerves that connect the central nervous system with the body and vice versa). Our nervous system is functionally divided into the

5 Porges has added a fifth mechanism: Play, a blend of social engagement and mobilization states. See Stephen W. Porges, The Polyvagal Theory: Neurophysiological Foundation of Emotions, Attachment, Communication, and Self-Regulation (New York: W.W. Norton \& Company, 2011), 278. 
autonomic and somatic nervous systems. The somatic nervous system controls our muscle movements. The autonomic nervous system automatically maintains our body functions and is divided into the enteric, the sympathetic and the parasympathetic nervous systems. The enteric system regulates gastrointestinal motility and secretion. The sympathetic system (speeds up body functions) and the parasympathetic system (slows down body functions) are what we use for neuroception.

Especially we use our tenth cranial nerve (the vagus nerve), which is part of our parasympathetic nervous system, for neuroception. Our vagus nerve has two systems-an old dorsal vagal system present even in reptiles and a new ventral vagal system present only in mammals (see Tab.4.1). Neuroception works from newest to oldest.

Table 4.1

The Nervous System.

The nervous system is anatomically divided into the central and the peripheral nervous systems.

1. Central Nervous System (CNS)

- Brain

Cortex: Thought-organizes experiences

Limbic System: Feeling-regulating emotions, memory (autobiographical narrative),

attachment attuning

Brain stem: Instincts-basic survival functions, automatic reactions

- Spinal Cord: brain-body communication

2. Peripheral Nervous System (PNS): spinal and cranial nerves that connect the CNS with the body and vice versa

The nervous system is functionally divided into the autonomic and somatic nervous systems.

1. Autonomic Nervous System: automatically maintains body functions

- Sympathetic: speeds up body functions and responds to perceived danger

- Parasympathetic: slows down body functions

Dorsal Vagal System: responds to life threat

Ventral Vagal System: responds to social cues (Ventral Vagal System is unique to mammals)

- Enteric: regulates gastrointestinal motility and secretion

2. Somatic Nervous System: controls muscle movement

Sources: Louis Cozolino, The Neuroscience of Human Relationships: Attachment and the Developing Social Brain (New York: W. W. Norton, 2006); Stephen W. Porges, "Love: An Emergent Property of the Mammalian Autonomic Nervous System," Psychoneuroendocrinology vol. 23 (1998), 837-61; Stephen W. Porges, "The Polyvagal Theory: Phylogenetic Substrates of a Social Nervous System," International Journal of Psychophysiology vol. 42 (2001), 123-46; Allan Siegel and Hreday N. Sapru, Essential Neuroscience (New York: Lippincott Williams \& Wilkins, 2006), 5. 
First-with our newest ventral vagal system-we assess for safety, which allows us to connect with others. When our neuroception detects safety, it puts our bodies in a physiological state of calm. A physiological body-state of calm promotes social engagement (Porges, 2003).

Second, we assess for danger. When our neuroception detects danger, it activates our bodies using our sympathetic nervous system. This activation increases heart rate, elevates blood pressure, increases blood circulation in our muscles, releases glucose from our liver for extra fuel and elevates stress hormones-all of which mobilize fight reactions or active avoidance reactions (Porges, 2001). These body-states of fight/flight are states of fear. Physiological states of fear are incompatible with compassionate social communication.

Third-with our oldest dorsal vagal system-we assess for life threat. When our neuroception detects life threat, it produces body-states of immobilization such as death feigning, passive avoidance or behavioral shutdown. These body-states of shut down in immobilization with fear cannot be maintained long in human beings because they are incompatible with human life.

When appropriate, we assess whether we can immobilize without fear. Immobilization without fear enables us to restore ourselves and enables women to give birth, to nurse infants and to engage in reproductive behaviors. For these purposes, human beings are created with the hormone oxytocin. Oxytocincalled the love hormone by a world authority on oxytocin, Kerstin Uvnäs Moberg, M.D., Ph.D. (2003) -is released when neuroception detects safety in situations that require pair bonding. In these situations, oxytocin co-opts the immobilization with fear response freeing the oldest dorsal vagal system and allowing our bodies an immobilization with love response.

All of these assessments-for safety, danger, life threat or immobilization without fear-happen in a matter of seconds and without our awareness. Awareness follows after neuroception.

Newborn human infants are capable of neuroception. When a newborn's smile is met with a smile, the newborn's innate desire to connect intersubjectively with another is activated and fueled. The desire of the smiling other is also activated and fueled. Likewise, when the infant's desire to be touched or talked to is met with experiences of being touched or talked to within dyadic resonance, desire is activated to establish secure attachment relationships. In the words of neurologist Robert Scaer, "It's very likely that childhood attunement and the lack of childhood trauma facilitate autonomic and emotional stability throughout... one's life, instilling a baseline state of empowerment and self-capacity through adulthood" (Scaer, 2012, 144).

Secure attachment relationships provide a sense of safety. Relationships become places to feel worthy and loved. The cocreation of secure attachment 
relationships is the essential task of the first year of human life. In the process of successfully completing this task, relationships become places of love.

The scientific discoveries about the role of the vagal system and oxytocin can be understood as the "precursors of love"-precursors of affectio iustitiae. Other mammals are equipped biologically for affectio commodi-desire for selfpreservation and kinship preservation. Indeed, primatologist Frans de Waal (2009) offers evidence of self-sacrifice, sympathy, cooperation and a sense of fairness in mammals. But, affectio iustitiae-desire focused outward toward loving justlyrequires something else. It requires self-control to choose freely what conforms to right reason. As philosopher Mary Beth Ingham puts it "We can learn much from Scotus's presentation of the moral life. When moral excellence is not primarily an intellectual achievement, but rather the perfection of selfless love, then the human heart is called to do what it does best: respond rationally to what is good. Self-controlled rational love is the highest moral response. In the universe created freely out of a divine act of rational love, a universe overflowing with goodness, the human will moves gradually toward better and better choices about the many goods which surround it. To be a moral agent for Scotus is to develop continually the ability to love in an orderly manner. For this perfection, the will is naturally and rationally well-equipped" (Ingham, 1996, 151).

We learn about free will in chapter 5 . In preparation, let us expand our understanding of love and desire-beginning with love.

\section{LOVE}

One understanding of the Biblical creation story underscores that when God breathed into humans the breath of life, God breathed into us the desire "to be," to be in relationships of love, to be in the creative process of bringing love into the world so that a morality of compassion prevails.

Scotus and love. Scotus discerns that ordered love defines the most perfect morality. Indeed, he places love at the center of morality (Ingham, 1996). His anthropology of human nature is optimistic: by definition we are beings capable of loving (Ingham, 1996, 117). Moral perfection is the perfection of loving (Ingham, 1996, 24). In turn, "moral living is ... the fullest expression of God's infinite love" (Ingham, 1996, xiii).

Love allows people to dance together forming harmonious relationships. Scotus values relationships. He affirms, "we have a natural desire for wholeness which can only be achieved by means of a relationship to God and to others" (Ingham, 1996, 118). As we learned in chapter 3, current neuroscientific jargon calls Scotus's idea of moral living as relational living: intersubjectivity. Scotus calls it mutuality. "The entire journey of human living, from internal choices to external actions, culminates in mutuality with God and with all persons" (Ingham, 1996, xix). Dr. Dawn M. Nothwehr, O.S.F. puts it this way: "Thus, we have, in Scotus, 
the grounding for mutuality as the primary foundational and normative manner for human relationships-with God, with other humans and with the cosmos. Indeed, mutuality names the human/divine partnership in ongoing creation and redemption" (Nothwehr, 2005, 60).

Scotus scholar Mary Beth Ingham sees implications of Scotus's relational living on many levels. On the personal level, she sees that Scotus envisions the self as a moral person in mutual relationship with another. "Mutuality between God and human persons is a freely chosen act initiated by God ... " (Ingham, $1996,20)$. Morality culminates in mutuality where each person freely chooses to seek the good of another and in so doing experiences profound delight (Ingham, 1996, 145). On the community level, Scotus's mutuality-according to Inghamimplies society's responsibility for promoting a moral community in which values are sustained, persons are respected and life is defended. On the national level, it implies relational living as expressions of love and forgiveness. And, on the international level, it implies relational living being realized in cooperation between producers and consumers of goods (Ingham, 1996, 149-150). Indeed, "training for goodness can only occur in mutuality with others who long for the same high quality of moral living" (Ingham, 1996, 39).

Psychiatry, neuroscience and love. Neuroscience grounds Scotus's insight about love on quantitative empirical results beginning with attachment theory research and continuing with studies of human neuroanatomy and body physiology. It is no surprise that "attachment" is a component of most definitions of love. In Webster's Seventh New Collegiate Dictionary, for example, love is defined as "warm attachment" and "the object of such attachment."

Secure attachment relationships become the templates-internal working models of the attachment relationships with our primary caregivers-that are stored in our brains and expressed through our moral bodies. Our bodies express these encoded strategies of emotional regulation that non-consciously influence our relationships throughout our lives and into future generations. These encoded strategies influence our relationships with others and with God. They are also crucial motivators "of moral actions and ... inextricably linked with moral evaluations and judgments [assessments]... . deeply influenced by social learning and by individual biological differences" (Moll et al., 2009, 126-127).

Secure attachment bonds promote morality in another away. They lay the foundation for empathy-an early essential prerequisite to morality. Empathy facilitates reciprocity, valuing and respecting one another's feelings and recognizing that both have the same and different feelings. As Philosopher of Mind, Evan Thompson, expresses it, ". . empathy provides the source of that kind of experience [moral experience] and the entry point into it" (Thompson, 2005, 269). More explicitly Thompson writes, "Empathy in the moral sense is a basic cognitive and emotional capacity underlying all the moral sentiments and emotions one can have for another. The point here is not that empathy exhausts 
moral experience, for it certainly does not, but that empathy provides the source of that kind of experience and the entry point into it" (Thompson, 2007, 401).

Professor of Psychology Martin L. Hoffman has proposed four developmental levels of empathy. His developmental levels have been summarized by others as follows: (1) global empathy emerges in the first months of life and is seen in the reflexive crying of infants in response to the crying of other infants, (2) egocentric empathyemerges in the second year of life and is seen in behaviors of comforting others in ways that would ameliorate the toddler's own distress, (3) empathy for another's feelings emerges during the third year of life and (4) empathy for another's life condition emerges by late childhood (Hastings et al., 2006, 487). The fact that children from many cultures show this temporal concordance in the emergence of empathy "implies a biologically based preparedness to judge [assess] acts as right or wrong" (Kagan, 1987, x).

The love hormone, oxytocin, has been linked to the subjective experience of empathy (Zak, 2011). This brings us back to Porges's theory about the vagus nerve and the physiology of morality. Oxytocin affects both our body (especially our heart and our vagus nerve) and our brain (especially our higher brain functions) producing calmness and a positive mood. It informs our emotional regulation of fear/anxiety and approach/withdrawal behaviors promoting a body-based state of calm where a subjective experience of empathy can thrive. Oxytocin is, thus, an important component in our human physiological moral compass because of its role with empathy.

Psychologically, empathy involves affective expression (an emotional joining in) and cognition (apprehending or understanding the other's experience). The appearance of empathy in the first months of life reflects "a view of human nature that serves as a continued reminder of our initial positive potentials" (Zahn-Waxler \& Robinson, 1995, 168). Brain scientist Donald Pfaff goes so far as to say, "that some rules of behavior are universally embedded in the human brain-that we are 'wired for good behavior"' (Pfaff, 2007, 2). We are wired for compassion that readies our bodies to support others.

Scotus, psychiatry and neuroscience. Can you see how Scotus's desire that focuses outward may be grounded in secure attachment relationships? Can you see how secure attachment relationships may be mediated anatomically by our mirror neurons and physiologically by our newest ventral vagal system that detects safety in others and readies our bodies for social engagement? Indeed, Scotus's desire focused outward seems substantiated by the discoveries of psychiatry and neuroscience about our human attachment relationships, anatomy and physiology.

Scotus's desire that focuses inward also seems grounded in scientific findings. Our autonomic nervous system including our oldest dorsal vagal system detects danger and life threat. It readies our bodies physiologically for selfpreservation-either fight/flight or immobilization. 
It seems, therefore, that human beings are biologically constituted to desireboth inwardly for our self-preservation and well-being and also outwardly for our love of the good.

Given this foundation —established by Scotus, psychiatry and neurosciencewe are ready to delve more deeply into understanding desire.

\section{DESIRE}

Professor of Physiology Vittorio Gallese defines desire as "openness to others" (Gallese, 2011, 88). Human beings are created to connect openly with others. In so doing we know others directly through interpersonal imitation. Imitation is an invitation to engage with another. From the beginning of life we connect through imitation.

Through intersubjective imitation - the sharing of physiological and emotional body-states with another-we cocreate our self and come to understand the other. Human beings begin life as shared minds and bodies. "[T]he I-Thou relation provides the basic ground for our cognitive/affective development, hence for our truest and most intimate abilities as social individuals capable of mutual recognition and understanding"(Gallese, 2011, 98). "The I-Thou relation is shaped by bidirectional interaction processes, hence 'self' and 'other' are originally co-constituted" (Gallese, 2011, 99).

This understanding of desire is consistent with Scotus's view of desire having two orientations: one focused inward (desire for self-preservation, selfperfection and happiness) and one focused outward (desire for our neighbor's good). Scotus discerned the felt equivalence between self and others that human beings experience when they imitate another.

Scotus's insight is beautifully expressed by neuroscience. "The Golden Rule, 'Treat thy neighbor as thy self' at first occurs in action, through imitation. Without an imitative mind, we might not develop this moral mind. Imitation is the bud, and empathy and moral sentiments are the ripened fruit-born from years of interaction with other people already recognized to be 'like me.' To the human infant, another person is not an alien, but a kindred spirit-not an ' $\mathrm{t}$ ' but an embryonic 'Thou'"' (Meltzoff, 2002, 36).

In summary, desire is an innate psychological, biological and spiritual urge to connect with others and with all of creation. When our desire is met by others with compassion, our urge is ignited, nourished and grows. "Every act of love is a new beginning, a new creation" (Delio, 2011, 119).

When our desire is not met with compassion, our urge is blocked, starved and misdirected. This does violence to our being.

Both Scotus's and science's understanding of desire-with their emphasis on I-Thou intersubjectivity-point to the idea that our human desire gives rise to both compassion and violence. 
"What!" you exclaim. "Violence? How can that be?"

Before we answer these questions, we must address the issue of free will. We must clarify how Scotus conceptualizes free will with regard to understanding our moral selves and we must understand how psychiatry and neuroscience present free will in terms of human inner moral life. 